Print ISSN: 2234-3040 / Online ISSN 2234-3059

doi:10.13106/eajbm.2018.vol8.no4.17

\title{
Roles of Social Identity Verification in the Effects of Symbolic and Evaluation Relevance on Chinese Consumers' Brand Attitude
}

\author{
Nak-Hwan Choi*, Huimin $\mathrm{Xu}^{* *}$, Zhuoqi Teng*** \\ Received: August 20, 2018. Revised: August 28, 2018. Accepted: October 05, 2018.
}

\section{Abstract}

Purpose - Current study aimed at investigating the symbolic and evaluation relevance to global luxury brands as the causes of inducing social identity verification, and also explored whether the social identity verification will affect the attitude toward the brands.

Research design, data, and methodology - 323 questionaries from Chinese consumers were used to test hypotheses by structural equation model of AMOS 22.0.

Results - First, social identity verification positively affected on the brand attitude. Second, both the symbolic relevance and the evaluation relevance positively affected on social identity verification. Third, the mediation roles of social identity verification were identified. Social identity verification played a full mediation role in the effect of the symbolic relevance on the brand attitude, and played a partial mediation role in the effect of the evaluation relevance on the brand attitude.

Conclusions - This study could contribute to the advancement of theory concerned with the roles of consumers' social identity verification which induces positive attitude toward the global luxury brands. Global brand managers in China should try to search ways by which consumers can feel both the symbolic relevance and evaluation relevance to their luxury brands, and should make efforts to improve the symbolic relevance and evaluation relevance to their brand.

Keywords: Evaluation Relevance, Social Identity Verification, Symbolic Relevance, Brand Attitude.

JEL Classifications: C83, L81, M31, P46.

\section{Introduction}

There is a set of meanings hold by people about who they are, which group they belong to, and their roles in a specific social situation (Burke, 2004). Social identity which means the special roles in a particular social situation (Stets, 2006) could play roles in leading one's behavior. People could compare their social self-meanings they hold in their social situation with their social identity standard (Burke, 1991). The accordance between the social

* Corresponding Author, Professor, Department of Business Administration, Chonbuk National University, Jeonju, Korea. Tel: +82-63-270-2998, E-mail: cnh@jbnu.ac.kr

** Master, Chonbuk National University, Jeonju, Korea. E-mail: xuhuimin0530@naver.com

*** Doctoral Student, Chonbuk National University, Jeonju, Korea. E-mail: 378391734@qq.com self-meanings and social identity standards will help experience positive emotion whereas the disaccordance between them will lead to the place of feeling negative emotion (Burke \& Harrod, 2005). And in the case of accordance (disaccordance) their social identity could be verified (not verified).

Past research has focused on consumers' personality related to environmental stimuli (Aaker, 1997), and their embodying effects on consumers' inducing self-meanings reflecting their ideal identities (Belk, Bahn, \& Mayer, 1982), and motivation effect of consumers' identity on expressing their selves (Escalas \& Bettman, 2005), categorization of goods owned by consumers as self (Weiss \& Johar, 2016), social approval in building social relationship (Berger, 2014). However, social identity verification can matter since it could play roles in the effects of brand traits on brand attitude.

Consumers' association coupled with global brands at a 
sociopolitically dynamic place could induce socially charged interpretations about the brands. It could help consider the importance of them in view of ingroup-related opinion. The opinion can often become information in the process of building consumer identity and forming attitudes toward the global brands (Varman \& Belk, 2009).

Consumers also can show their social identity to others by using brands or products either consciously or unconsciously, and other observers can categorize or infer which group the consumers belong to by observing the brands or products he or she use (Escalas \& Bettman, 2003). When a brand is used to communicate one's social identity to others, the symbolic relevance works (Belk, 1988; Shavitt \& Nelson, 2000). And consumers could identify how the brand is related to others' evaluation about their identities. When the usage of the brand influences on others' evaluating who they are, the evaluation relevance exists.

Under consumers' social circumstances, their social identities can be the factors that motivate them to take the identity-based behaviors to express which group they belong to. And the social identity can be verified when their social self-meanings are perceived to be in accordance with social identity standards. Furthermore, consumers' brand attitude will be formed positively to the degree to which their social identity is verified by using the brand. However which aspects of using the brand could verify consumers' social identity has received little attention from previous research. It is necessary to explore the effects of such social identity relevance as the symbolic relevance and the evaluation relevance on the social identity verification which in turn, could affect brand attitude.

Conversational values of using global luxury brands in the respects of the symbolic and evaluation relevance might be a necessary condition for verifying consumers' social identity as well as their building and maintaining social relationship. Their social identities will become the motivators that help them take the social identity-based brand consumption behaviors to verify who they are or which group they belong to. It is necessary to explore how consumers' symbolic and evaluation relevance to the global brand affect the brand attitude. The focus of this research is given to such social identity relevance as symbolic relevance and evaluation relevance, and the social identity verification, which in turn, could affect consumers' attitude toward the global brands. Therefore, the purposes of this research are presented as followings.

First, the process of verifying social identity will be theoretically explored and the antecedents of the social identity verification will be identified.

Second, this research will investigate symbolic relevance and evaluation relevance as the causal factor of consumers' social identity verification.

Third, brand attitude will be investigated as an outcome of the social identity verification.
Last, it will be investigated whether the social identity verification plays mediation roles in the effects of the symbolic relevance and the evaluation relevance on the brand attitude.

This study will explore the mediation role of the social identity verification in the effect of the symbolic and evaluation relevance on global luxury brand attitude to contribute to social identity theory development, and could make managerial implication to global brand managers who do marketing to Chinese consumers.

\section{Theoretical Background and Hypotheses}

\subsection{Brand Attitude and Social Identity Verification}

Brand attitude could be defined as a consumer's general evaluation of brand, and the attitude could be positive or negative (Currás-Pérez, Bigné-Alcañiz, \& Alvarado-Herrera, 2009; Park, MacInnis, Priester, Eisingerich, \& lacobucci, 2010). And the identity conceptualized as the way of making a sense of some aspects of self-concept (Abrams, 1994; Hogg, 2003; Serpe, 1987; Stryker \& Burke, 2000; Tajfel \& Turner, 2004) is defined as a set of meanings which are hold by people for themselves to show who they are, which group they belongs to, and their roles in a specific situation (Burke, 2004). Therefore in the process of forming and changing brand attitude, consumers can consider their identities.

Each person has a repertoire of identities that includes one's individual-level identities and various social identities. In social identity theory, social identity is a person's knowledge that he or she belongs to a social class or group (Abrams \& Hogg, 1988). And consumers expect their identities seen by others to be same as those which show who they are (Swann, 1983). This process can be driven by identity-verification.

Consumers could derive their social self-views by observing others' reactions toward themselves. Once formed, the social self-views give meaning to their behaviors, thereby enabling them to make sense of such behaviors. The identity pursued by group members is called identity standard. People often use it as a reference to compare with the perceptions of their identity-relevant meaning based on the feedback from the interactive externals. When the perceived meaning is coincident with the identity standard, they will continue to behave according to the identity standard because their identities can be verified. But if the inconformity occurs, they will try to match the perceived meaning with the standard (Burke, 2004). This is a kind of identity-verification process.

Susceptibility to normative influence reflects a consumer's tendency to conform to others' expectations in order to gain rewards or to avoid punishment from others, to be identified 
with the others (Bearden, Netemeyer, \& Teel, 1989). The susceptibility to normative influence leads consumers to place more importance on socially visible benefits rather than on private benefits, and may contribute to luxury consumptions that are publicly visible. Luxury brand as a sign of prestige and social status could appeal to the consumers who are susceptible to the normative influence especially when the consumptions of the brand product are visible to others.

As similar interests, attitudes, or experiences of consumers in similar social groups are more likely to help them build and communicate relationships with each other, effective social identity communication can help them build relationships with similar others (Jensen, Davis, \& Farnham, 2002). Self verification theory suggests that people are more satisfied and likely to participate in a relationship when their salient identities are confirmed by others in a group (Swann, Chang-Schneider, \& McClarty, 2007). A consensus on identity between consumers can help develop a sense of understanding and coherence, and a higher fit between individual consumers' self-view and others' evaluation yields a closer relationship among them (Swann, Milton, \& Polzer, 2000). Effective social identity communication could be the bases of verifying individuals' social self, and facilitate and promote them help similar others because of self-esteem felt at the communication (Bock, Zmud, Kim, \& Lee, 2005).

In consumers' lives, social elements (people and groups) are included into the situations and contexts where they evaluate their own traits or abilities (Mussweiler \& Bodenhausen, 2002). Prior research that has examined social environment as a source of evaluating self found that people often assimilate their own traits to those of ingroup members, and contrast them from those of outgroup members (Ledgerwood \& Chaiken, 2007). Social self category can often be judged in contrast from their traits or abilities it excludes, but in assimilation to them it includes (Bless \& Schwarz, 2010).

Choosing a global luxury brand with a desirable trait as a signal of consumers' using the trait could be strategically interpreted by them (Park \& John, 2010; Weiss \& Johar, 2016). Using a global luxury brand with such desirable traits as symbolic or evaluation relevance can positively affect how consumers judge their social identity verification on the traits of the brand. From this view, the brand ownership can boost social identity verification along the brand traits only to the extent that consumers choose the brand and thus can interpret using it as a diagnostic signal that conveys information about their social identity verification.

On the other hand, the relationships with others are greatly emphasized by Chinese people. They strive to maintain good relationships with others and to behave in accordance with their social standing and positions (Buckley, Clegg, \& Tan, 2006). Chinese consumers place great emphasis to the social meanings of products or brands, and like to use them to develop social relationships (Wang \&
Lin, 2009).

Chinese consumers might be motivated to utilize global luxury brands to communicate their social standings. The dominating social norms among them could encourage luxury consumption. Therefore, a direct, positive effect of the susceptibility to normative influence on brand attitudes is likely to occur to them (Zhan \& He, 2012).

However, identity-verification process can influence the Chinese consumers' behaviors. When the feedback that someone gets from others successfully verifies the standard of the identity, he or she will experience positive emotions; but if the feedback does not verify the standard, he or she will experience negative emotions (Carter, 2013). Once the feedbacks from the external situation threaten people's confidence of their identity standard, people will desire to verify their identification with the standard more (Swann et al., 2007). For example, some woman could want that others see she is thin and healthy, but others could say that she is a little bit fat, then this difference may lead her to pursue thin and healthy identity more. She may have a positive attitude toward the food which is linked with the descriptions like "healthy" "low calorie" and so on (McFerran, Dahl, Fitzsimons, \& Morales, 2009).

Based on the past research like the before, when the feedback about using a brand that Chinese consumers receive from others successfully verifies their identity standard, they will form positive attitude towards the brand.

$<\mathrm{H} 1>$ Social identity verification perceived at a brand usage will positively affect the brand attitude.

\subsection{Identity Relevance to Brand}

Consumers' motives for luxury consumption in collective cultures are driven mainly by social needs (Wong \& Ahuvia, 1998). Group harmony and individual's responsibilities to their ingroup are emphasized in collective cultures (Kim \& Markus, 1999). Susceptibility to normative influence as a tendency to conform to social norms might exert great influence on consumers in China because of its collective culture. Chinese social norms could guide Chinese consumers' behavior. To develop and maintain self-identity they may integrate symbolic meanings of luxury brands into their own identity and use these brands (Wiedmann, Hennigs, \& Siebels, 2009). This study attempts to explore the influence of the symbolic relevance and evaluation relevance to the brands on Chinese consumer's social identity verification.

China's economy growth (Lee \& Wang, 2018) and enormous population are the main reasons why China has become attractive markets for global luxury brands in the world (Cavender \& Rein, 2009). The luxury brand marketers think China's middle-class consumers are important targets (Unger, 2006). However, previous researches have not given much attention to the effects of the symbolic and evaluation 
relevance on Chinese consumers' global luxury brand consumption. Values of keeping up with others are supported by individuals under harmony culture. And social equality, justice, altruism and integrity are pursued by people in egalitarianism country (Schwartz, 2006). In China as vertical collectivist societies, Chinese people are likely to subordinate their own goals to their ingroup goals, and prefer the competition abilities of their ingroup to those of their outgroups (Triandis \& Gelfand, 1998). In view of the China's cultural characteristics, China is belonged to Confucian culture. Therefore, Chinese people are more likely to perceive social influence highly, and they might give little attention to individual dogmatism opposed to the social harmony. Therefore, to persuade Chinese consumers, global luxury brand marketers should know how to adapt to such social influencer as the symbolic and evaluation relevance considered by them.

Relevance is generally explained by the terms of instrumentality relationship between consumer's identity and the object related to the identity (Reed, Forehand, Puntoni, \& Warlop, 2012). It was confirmed that a brand has its own symbolic meanings (Levy, 1959). Brand can signify not only oneself but also a group, country, or culture (Anisimova, 2016). Consumers can use the brand's meaning to construct their identities, especially when the meaning is widely recognized by the people who use or even not use it (Escalas \& Bettman, 2005). However, with the development of research on identity signaling, it has been suggested that not all the brands can be equally used as a tool of signaling his or her identity. For example, if you want to show that you are a rich woman who belongs to the upper social class, you may not use the miscellaneous handbag brands but use the famous handbag brands. Escalas and Bettman (2005) attributes the brand usage differences to brand symbolism which is defined as the brand's ability of communicating something about the person's identity. The identity relevance to a brand means that the brand can be associated with one's own identity when it symbolizes his or her personal characteristics (Aaker, 1997). The relevance can be perceived when the specific characteristics of the brand help consumers express and realize their identities.

On the other hand, by using differences between the focus on individual and that on others, the type of identity relevances can be divided into individual identity relevance and social identity relevance (Reed et al., 2012). Since the focus of this study is given to the feedback from others about Chinese consumers' global brand usage, we will explore the influence of the symbolic relevance and evaluation relevance concerned with social identity on social identity verification.

\subsubsection{Symbolic Relevance to Brand}

People can perceive the world by participating in their society, and give meaning or value to the world's stimuli and others' behavior (Blunter, 1994). The symbol is a specific object to which there is the shared meaning or value acquired and learned with others in the society. The symbolic meaning is obtained through the process of socialization by interaction with others (Solomon, 1983). Symbolic relevance to brand makes sense when the possession of the brand communicates or reinforces consumer's identity in others' eyes (Shavitt \& Nelson, 2000). Symbolic congruence of a brand between consumers can be used to explain consumer attitude toward the brand (Sirgy, Grewal, \& Mangleburg, 2000).

In addition, the symbolic meaning can play an important role in connecting self and others in the society. Brands provide "a social stock of knowledge that people use in typifying those they meet" (Shavitt \& Nelson, 2000, p.40). Individual's purchase and consumption of a brand can be inferred by the other person as a symbol of what the individual is trying to symbolize, and can be used as a tool by which others can classify what group the individual belongs to (Escalas \& Bettman, 2003). For example, people often regard the man who wears Rolex watch as success man. So man could make efforts to have the Rolex watch, since the watch can verify that he belongs to the group of success man. Possessing or using the Rolex watch could verify to others that he belongs to the success man group.

As the symbolic relevance to a brand works in communicating one's social identity to others, the social identity could be verified by using the brand. Based on these views, we formally make the hypothesis as follows.

$<\mathrm{H} 2>$ Symbolic relevance to a brand will positively affect social identity verification.

\subsubsection{Evaluation Relevance to Brand}

Another social identity relevance is evaluation relevance. After specifying and clarifying brand information, consumers could identify whether the brand is related to others' evaluation about their identity. When the usage of the brand influences on others' evaluating who they are, the evaluation relevance exists.

The evaluation relevance to a brand indicates the degree to which the brand is associated with others' evaluation about the consumer's identity. For example, women as members of white-collar group can contact with a lot of advertising for women's cosmetics brand in their daily life. However, the absence of clarity and specificity at the evaluative content of the identity could be an inadequate basis for consumers' choice and by thus could make fails to find differences between the available brands (Kallgren, Reno, \& Cialdini, 2000). If these advertisements do not provide clear benchmark of the brand considered in view of the white-collar group, they will not perceive the possibility of getting positive feedback from the others of the group when they use the brand. In this situation, the lack of the 
white-collar identity relevance to the brand in the advertisements will not provide evidence that the brand verifies the social identity of the women.

Therefore, the evaluation relevance as the degree to which the brand is associated with other's evaluation about the consumers' identity can influence their social identity verification. Based on this, we make the hypothesis as follows.

$<\mathrm{H} 3>$ Evaluation relevance to a brand will positively affect social identity verification.

Taken together, the research model can be delineated by $<$ figure $1>$.

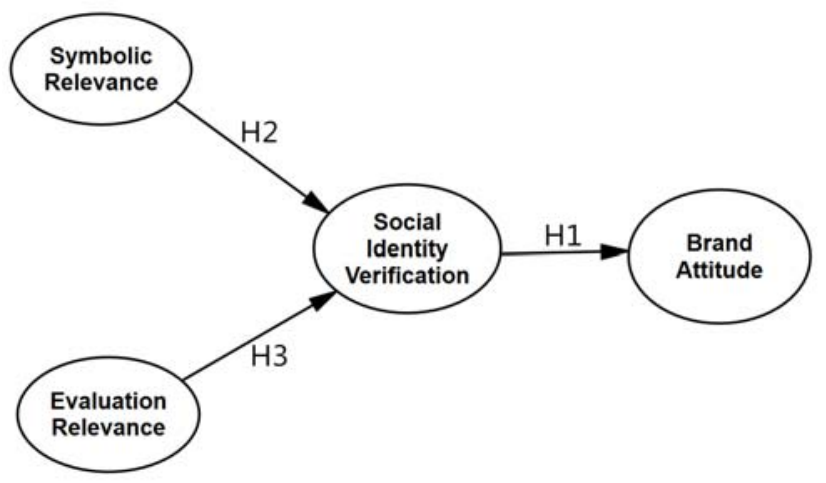

<Figure 1> Research Model

\section{Empirical Study}

\subsection{Measures of Constructs}

\subsubsection{Measures of Symbolic Relevance and Evaluation Relevance}

Three items are used to measure the symbolic relevance based on Reed II et al.(2012). The three items include 'My friends know that I'm using the brand(SR1),' 'The opinions about the brand are same between my friends and me(SR2),' 'My friends and I share the meaning of using this brand(SR3)' answered on 7-point scale ( $1=$ not at all, $7=$ very much). In addition, three items on 7-point scale are used to measure the evaluation relevance. The three items include 'My friends think the brand fits me(ER1),' 'I think my friends like the brand(ER2),' 'My friend say that it's good for me to use the brand(ER3).'

\subsubsection{Measures of Social Identity Verification}

In the process of verifying individuals' social self they could strive to make others see themselves in the way they see themselves (Swann, 1983). Their social identity pursuit is driven by their social self verification. Positive feedbacks from others successfully verifies that their social self fits the social standard. Based on Swann(1983), four items on 7-point scale are used to measure the social identity verification. The four items include 'I can show who I am to others by talking about this brand(SIV1),' 'I can imitate the activities of this brand to show who I am(SIV2),' 'My friends know who I am by listening to my story about the brand(SIV3),' 'I feel that I show my identity to others through the brand(SIV4).'

\subsubsection{Measures of Brand Attitude}

To measure the brand attitude, four items on 7-point scale are employed based on the research of Holbrook and Batra(1987). The four items include 'I like the brand(BA1),' 'I think the brand is valuable(BA2),' 'I feel positive toward the brand(BA3),' 'I react favorably to the brand(BA4).'

\subsection{Questionnaire, Pretest and Data Collection}

In the questionnaire, there are the questions to check whether participants had experience of using global handbag or wallet brand, and the question asking to write down the brand name of the handbags or wallets they used before.

Using the items for each construct mentioned before, we developed the questionnaires in English and then translated it into Chinese. In order to find and correct errors in the translated questionnaire, 64 Chinese undergraduate students enrolled in marketing class participated in the pretest. We revised the questionnaires based on the errors explored in the pretest.

In order to collect the data from all of the provinces of China, professional questionnaire website, Wenjuanxing which is one of the largest questionnaire websites in China was used. The questionnaire was uploaded to the website and $3 R M B ¥$ for each participant was paid to the website. After finishing the questionnaire, all the participants received small gift certificates and various lucky draw opportunities sent by the website. Chinese consumers are perceived to be lacked in knowledge about luxury brands when naming only one or two luxury brands in any product category (Atsmon \& Dixit, 2009). In the main survey we checked whether the participants have experienced global luxury brands in handbag or wallet product category. We collected 435 questionnaires from Chinese consumers in China. And 112 of them was removed because the respondents said that they had no experience of using global handbag or wallet brand. 323 questionnaires were used in the final analysis.

The demographic information of participants was as follows. There were female participants $(\mathrm{N}=219,67.8 \%)$. As for the age, the most participants were at 21-30 years old $(57.6 \%), 2.5 \%(\mathrm{~N}=8)$ were under the age of $20,29.7 \%(\mathrm{~N}=96)$ were at $31-40$ years old, $7.4 \%(\mathrm{~N}=24)$ were $41-50$ years old, 
and $2.8 \%(\mathrm{~N}=9)$ were over the age of 50 . As for their provinces of residence in China, FuJian( $\mathrm{N}=50,15.5 \%)$ took the first place, and followed by ShanDong $(\mathrm{N}=33,10.2 \%)$, HeNan(N=29, 9.0\%), GuangXi(N=27, 8.4\%), GuangDong(N=24, $7.4 \%)$, JiangSu( $\mathrm{N}=19,5.9 \%)$, BeiJing $(\mathrm{N}=18,5.6 \%)$, ZheJiang $(\mathrm{N}=15,4.6 \%)$, and other provinces $(\mathrm{N}=108,33.4 \%)$.

In the questionnaires, the participants were asked to write down the brand name of the handbags or wallets they used before. Louis Vuitton( $\mathrm{N}=54,16 . \%)$ was most mentioned and the following brands were Coach $(\mathrm{N}=49,15.2 \%), \operatorname{MCM}(\mathrm{N}=21$, $6.5 \%)$ Michael Kors $(\mathrm{N}=20,6.2 \%)$, Chanel( $\mathrm{N}=15,4.7 \%)$, Gucci( $\mathrm{N}=15,4.7 \%)$, Dior( $\mathrm{N}=10,3.1 \%)$, Burberry $(\mathrm{N}=9,2.8 \%)$, Prada( $\mathrm{N}=9,2.8 \%)$, Nike( $\mathrm{N}=9,2.8 \%)$, Calvin Klein( $\mathrm{N}=9,2.8 \%)$, and other brands( $\mathrm{N}=103,31.9 \%)$.

\subsection{Reliability and Validity}

Before testing the hypotheses, we used SPSS 22.0 program to check the reliability and validity of the items for each construct used in this study. In order to ensure the reliability, Cronbach's $\alpha$ was used to check the internal consistency. And then confirmatory principal component analysis based on Varimax was conducted to explore principal components. The analysis result is shown in <Table $1>$. Four components such as brand attitude $(\alpha=.958)$, social identity verification $(\alpha=.861)$, symbolic relevance $(\alpha=.861)$, and evaluation relevance $(\alpha=.880)$ are shown as expected(<Table $1>)$.

\subsection{Correlations among Constructs}

The results of analyzing correlations among the constructs are shown in <Table 2>. The squares of each correlation coefficient except the correlation between evaluation relevance and symbolic relevance are below the values of AVE. And all the AVEs are above .5.

The correlation coefficient of evaluation relevance and symbolic relevance is .906 . The symbolic relevance exists when people around us share the same meaning of the same things, while the evaluation relevance exists when the usage of the brand influence others' evaluation on himself or herself. In the items used to measure the symbolic relevance there are the meanings as follows. I and my friends share the same symbolic meaning of the brand used by me. whereas in the items used to measure the evaluation relevance there are the meanings of the brand being fit or good to me which come from others' evaluation. Therefore, the symbolic relevance is conceptually different from the evaluation relevance(<Table $2>)$.

<Table 1> Results of Analyzing Components

\begin{tabular}{|c|c|c|c|c|c|c|}
\hline \multirow{2}{*}{ Construct } & \multirow{2}{*}{ Item } & \multicolumn{4}{|c|}{ Component } & \multirow{2}{*}{ Cronbach's $\alpha$} \\
\hline & & 1 & 2 & 3 & 4 & \\
\hline \multirow{4}{*}{ Brand Attitude } & BA4 & .858 & .261 & .238 & .248 & \multirow{4}{*}{.958} \\
\hline & BA3 & .836 & .285 & .200 & .288 & \\
\hline & BA2 & .823 & .317 & .254 & .203 & \\
\hline & BA1 & .799 & .298 & .230 & .271 & \\
\hline \multirow{4}{*}{$\begin{array}{l}\text { Social Identity } \\
\text { Verification }\end{array}$} & SIV4 & .335 & .832 & .220 & .210 & \multirow{4}{*}{.861} \\
\hline & SIV1 & .292 & .822 & .229 & .240 & \\
\hline & SIV3 & .195 & .807 & .293 & .209 & \\
\hline & SIV2 & .343 & .802 & .216 & .243 & \\
\hline \multirow{3}{*}{ Symbolic Relevance } & SR1 & .283 & .218 & .826 & .174 & \multirow{3}{*}{.861} \\
\hline & SR3 & .229 & .418 & .695 & .235 & \\
\hline & SR2 & .250 & .279 & .663 & .487 & \\
\hline \multirow{3}{*}{ Evaluation Relevance } & ER3 & .317 & .287 & .179 & .807 & \multirow{3}{*}{.880} \\
\hline & ER2 & .378 & .261 & .402 & .665 & \\
\hline & ER1 & .349 & .360 & .400 & .594 & \\
\hline \multicolumn{2}{|c|}{ Eigen value } & 3.664 & 3.581 & 2.408 & 2.232 & \\
\hline \multirow{2}{*}{\multicolumn{2}{|c|}{$\%$ of Variance Explained }} & 26.169 & 25.582 & 17.201 & 15.940 & \\
\hline & $\%$ of Variance Cumulated & 26.169 & 51.750 & 68.951 & 84.831 & \\
\hline
\end{tabular}

<Table 2> Results of Analyzing Correlations and AVE

\begin{tabular}{|c|c|c|c|c|}
\hline AVE & Evaluation Relevance & Symbolic Relevance & Social Identity Verification & Brand Attitude \\
\hline Evaluation Relevance & .742 & & & \\
\hline Symbolic Relevance & .906 & .702 & & \\
\hline Social Identity Verification & $(.821)$ & $\begin{array}{l}.754 \\
(.569)\end{array}$ & .830 & .712 \\
\hline Brand Attitude & $(.590)$ & $\begin{array}{c}.741 \\
(.549)\end{array}$ & .872 \\
\hline
\end{tabular}

Note: The figures on diagonal line mean AVE, and the figures in ( ) are the squares of correlation coefficients. 


\subsection{Testing Hypotheses}

Individual consumers can use identity standard of his or her ingroup to compare with the meaning of their identity-relevant behavior. If the behavior-related feedback from the interactive externals is perceived to be in accordance with the meaning of consumers' behavior, the accordance will help them feel positive emotion (Burke \& Harrod, 2005), and they also do not recognize any conflict between their behavior and the feedback. They are more likely to continue the behavior. Therefore, the evaluation relevance to a brand can directly affect the attitude toward the brand.

And specific object could be the symbol to the degree to which there is the shared meaning about the object acquired or learned with others in their society (Solomon, 1983). A brand can also be the symbol under the condition that there is the brand meaning shared by the members of consumer's ingroup. In addition, the usage of the brand with the symbolic meaning can connect the brand user and others of the ingroup. The purchase and consumption of the brand play important roles in identifying whether he or she belongs to the ingroup or not (Escalas \& Bettman, 2003). Therefore, the symbolic relevance to a brand also can directly affect the attitude toward the brand.

In the process of testing hypotheses the direct paths from each of the exogenous variables to the brand attitude were added to the research model. And the AMOS 22.0 was used to test the model. The values of the result are $X$ 2=156.359 (DF=71, P=.000), GFI=.936, AGFI=.905, CFI=.982, $\mathrm{TLI}=.976, \quad \mathrm{FI}=.982, \mathrm{RFI}=.958, \mathrm{NFI}=.967, \mathrm{RMSEA}=.061$. The results of testing hypotheses are as followings.
First, the hypotheses 1 is accepted (Estimate=.407, $\mathrm{CR}=2.595, \mathrm{P}=.009$ ). Second, the hypotheses 2 is accepted (Estimate=.566, CR=3.571, $\mathrm{P}=.000$ ). Third, the hypotheses 3 is accepted (Estimate $=.198, \mathrm{CR}=3.969, \mathrm{P}=.000$ ).

Significance of each of the two direct paths will be discussed at the next mediation analysis(<Table $3>$ ).

\subsection{Mediation Effect Analysis}

In view of China culture as vertical collectivism (Schwartz, 2006), Chinese consumers are likely to give more attention to social influence than to individual dogmatism. Therefore, the symbolic and evaluation relevance to global brand consumption were theoretically reviewed to explore whether they could be the causes of verifying their social identity. At our research model, the social identity verification variable is used as mediator between each of the exogenous variables (symbolic and evaluation relevance) and the brand attitude. Therefore, it is necessary to check the mediation roles of the social identity verification variable.

One of the purposes of this research is to check the mediation role of the social identity verification. Based on the literature review like the above, the direct paths from each of the two types of relevance to brand attitude were added. The analysis of the mediation effect was conducted in bootstrap of the Amos. The symbolic relevance and evaluation relevance were used as exogenous variable, brand attitude was used as endogenous variables and social identity verification was used as mediation variable. And before the analysis, number of bootstrap samples was set to 500 and confidence intervals were adjusted to $95 \%(<$ Table $4>)$.

$<$ Table 3> Results of Testing Hypotheses

\begin{tabular}{|c|c|c|c|c|c|c|}
\hline Hypotheses & Path & Estimate & S.E. & C.R. & P & Results \\
\hline H1 & Symbolic Relevance(sr) $\rightarrow$ Social Identity Verification & .407 & .157 & 2.595 & .009 & Accepted \\
\hline H2 & Evaluation Relevance(er) $\rightarrow$ Social Identity Verification & .566 & .159 & 3.571 & .000 & Accepted \\
\hline H3 & Social Identity Verification $\rightarrow$ Brand Attitude & .198 & .050 & 3.969 & .000 & Accepted \\
\hline Direct Path & Evaluation Relevance $\rightarrow$ Brand Attitude & .642 & .124 & 5.161 & .000 & Accepted \\
\hline Direct Path & Symbolic Relevance $\rightarrow$ Brand Attitude & -.086 & .116 & -.738 & .460 & Rejected \\
\hline \multicolumn{2}{|c|}{ X2=156.359(DF=71, P=.000) GFI=.936, AGFI=.905, CFI=.982, TLI=.976, IFI=.982, RFI=.958, NFI=.967, RMSEA=.061. } \\
\hline
\end{tabular}

$<$ Table 4> Mediation Effects of Social Identity Verification

\begin{tabular}{|c|c|c|c|c|c|}
\hline $\begin{array}{l}\text { Dependent } \\
\text { variable }\end{array}$ & $\begin{array}{l}\text { Path } \\
\text { Type }\end{array}$ & Path & $\begin{array}{c}\text { Estimate } \\
\text { (Lower, Upper) }\end{array}$ & $\mathbf{p}$ & $\begin{array}{l}\text { Mediation } \\
\text { Type }\end{array}$ \\
\hline \multirow{2}{*}{ Brand Attitude } & Direct & Symbolic Relevance $\rightarrow$ Brand Attitude & $\begin{array}{c}-.092 \\
(-.471, .210)\end{array}$ & .503 & \multirow{2}{*}{ Full mediation } \\
\hline & Indirect & $\begin{array}{c}\text { Symbolic Relevance } \rightarrow \text { Social Identity Verification } \\
\qquad \text { Brand Attitude }\end{array}$ & $\begin{array}{c}.055 \\
(.006, .286)\end{array}$ & .023 & \\
\hline \multirow{2}{*}{ Brand Attitude } & Direct & Evaluation Relevance $\rightarrow$ Brand Attitude & $\begin{array}{c}.000 \\
(.366,1.093)\end{array}$ & .004 & \multirow{2}{*}{$\begin{array}{c}\text { Partial } \\
\text { mediation }\end{array}$} \\
\hline & Indirect & $\begin{array}{c}\text { Evaluation Relevance } \rightarrow \text { Social Identity Verification } \\
\qquad \rightarrow \text { Brand Attitude }\end{array}$ & $\begin{array}{c}.051 \\
(.028, .245)\end{array}$ & .009 & \\
\hline
\end{tabular}


Mediation analysis results are shown by <Table 4>. The direct path from symbolic relevance to brand attitude was not significant because the confidence intervals [lower bound, upper bound] included 0 and $p$ value was bigger than .05. However, the indirect path from symbolic relevance to social identity verification to brand attitude was significant $(\mathrm{Cl}=[.006, .286], \mathrm{p}<.05)$. So social identity verification played a full mediation role in the effect of the symbolic relevance on brand attitude.

The direct path from evaluation relevance to brand attitude is significant $(\mathrm{Cl}=[.366,1.093], \mathrm{p}=.004<.05)$ and the indirect path from evaluation relevance to social identity verification to brand attitude was also significant $(\mathrm{Cl}=[.028$, .245], $p=.009<.05)$. So social identity verification played a partial mediation role in the effect of the evaluation relevance on brand attitude.

People can use a social stock of knowledge provided by brands in typifying consumers they meet (Shavitt \& Nelson, 2000). And when brand consumption communicates or reinforces consumers' identity in the eyes of others, symbolic relevance to the brand exists (Belk, 1988; Shavitt \& Nelson, 2000). The purchase and consumption of the global luxury brand play important roles in typifying consumers or verifying who they are. Therefore, the full mediation role of social identity verification in the effect of the symbolic relevance on brand attitude means that the direct effect of the symbolic relevance on brand attitude is attenuated by the mediation role of social identity verification concerned with others' eyes. This point can be the reason why the direct effect from the symbolic relevance to brand attitude was not significant.

\section{General Discussion}

\subsection{Research Summary}

Consumers could behave differently based on their perceptions about who they are and the roles they play in the specific social situation. And they could expect their identities seen by others to be same as those pursued by themselves (Swann, 1983). Futhermore they might prefer the behaviors consistent with the social identity standards in their society to those inconsistent with the standards. Their behaviors will become different according to whether the feedbacks from others are positive or negative. If the feedbacks from the external situation weaken their confidence of the identity standard, they will desire to verify their identification with the standard more (Swann et al., 2007). The psychological symbols related to someone's self-meanings are perceived to be his or her self labels. The labels can be used to express his or her identities, which further influence on forming attitude or making decision (Oyserman \& Destin, 2010). However in the process of reviewing the results of the past research, it was found that the roles of social identity verification have not received much attention. Current study aimed at investigating the symbolic relevance and the evaluation relevance as the causes of inducing the social identity verification which will affect the attitude toward the relevance-concerned brand. This research also analyzed the mediation role of the social identity verification in the effects of the symbolic relevance and evaluation relevance on brand attitude.

Based on the theoretical literature review, hypotheses were developed. And then, 323 questionaries from Chinese consumers were used at the empirical study. Structural equation model was used to test the hypotheses and the results were explored as followings.

First, the results showed that social identity verification positively affected on brand attitude.

Second, both of the symbolic relevance and the evaluation relevance positively affected on the social identity verification.

Third, the direct path from the evaluation relevance to the brand attitude was significant whereas the direct path from symbolic relevance to brand attitude was not significant.

Fourth, the mediation effect of social identity verification was identified. Social identity verification played a full mediation role in the process of symbolic relevance affecting on the brand attitude, and did a partial mediation role in the process of evaluation relevance affecting on the brand attitude

\subsection{Theoretical and Managerial Implication}

In the past research about the effects of consumer's self-related brand traits on brand attitude, there has been the research about consumers' personality (Aaker, 1997), and motivation role of identity in self expression (Escalas \& Bettman, 2005), owned goods as self (Weiss \& Johar, 2016). There has been little attention to the role of social identity verification in the effects of the symbolic and evaluation relevance to global luxury brand on the brand attitude. The verification could play roles in the process of forming attitudes toward the global brands. In view of the roles, theoretical contributions of this research can be described as follows.

Both symbolic relevance and evaluation relevance were investigated as the causal factor of social identity verification. The social identity verification was explored to positively play mediation role in the effect of each of the symbolic relevance and the evaluation relevance on global luxury brand attitude. And the evaluation relevance directly affected on the brand attitude while symbolic relevance did not directly affected on the brand attitude. These findings could contribute to the development of theory concerned with consumers' social identity verification which induces positive attitude toward the global luxury brands in China.

Chinese consumers can verify their social identity through 
consuming the global luxury brands when the brands are perceived to have the symbolic relevance and evaluation relevance to the brand. Global brand managers should try to search the ways by which Chinese consumers can feel both the symbolic relevance and evaluation relevance to their luxury brands. The managers should make efforts to improve the symbolic relevance and evaluation relevance to their brand. Social self category can be perceived in contrast from the brand traits the self excludes, but in assimilation to them the self includes (Bless \& Schwarz, 2010). By attaching such desirable traits as symbolic or evaluation relevance to their global luxury brand, the managers should help the consumers judge their social identity verification to induce positive attitude toward the brand.

\subsection{Limitations and Future Research}

Although there are some contributions of this research, some limitations also exist.

First, this research used only global handbag and wallet brand as investigative categories. What the results will be for other brand categories is an open research question. So the future research which uses other brands categories as study objects is required.

Second, this research focused on Chinese consumers' attitude to global luxury brands. Whether the results will become same for native brands remains as a topic of future research.

Third, Almost $70 \%$ of the participants at the survey part of this study were females and over $55 \%$ were $22-30$ years old. So if the demographic characteristics of the participants are changed, whether the results change or not could become new topic for further research.

Fourth, individuals under Chinese collectivism culture may build their social relations with others based on sensing belongingness to them (Choi \& Dhakal, 2017; Choi, Park, \& Lim, 2018). Therefore interdependent Chinese consumers might adopt the self defined by their ingroup, which could be exploded by future research.

\section{References}

Aaker, J. L. (1997). Dimensions of brand personality. Journal of Marketing Research, 34(3), 347-356.

Abrams, D. (1994). Social Self-regulation. Personality and Social Psychology Bulletin, 20(5), 473-483.

Abrams, D., \& Hogg, M. A. (1988). Comments on the motivational status of self-esteem in social identity and intergroup discrimination. European journal of social psychology, 18(4), 317-334.

Anisimova, T. (2016). The effects of corporate brand symbolism on consumer satisfaction and loyalty: Evidence from Australia. Asia Pacific Journal of
Marketing and Logistics, 28(3), 481-498.

Atsmon, Y., \& Dixit, V. (2009). Understanding China's wealthy. McKinsey Quarterly, 4, 32-33.

Bearden, W. O., Netemeyer, R. G., \& Teel, J. E. (1989). Measurement of consumer susceptibility to interpersonal influence. Journal of consumer research, 15(4), 473481.

Belk, R. W. (1988). Possessions and the extended self. Journal of consumer research, 15(2), 139-168.

Belk, R. W., Bahn, K. D., \& Mayer, R. N. (1982). Developmental recognition of consumption symbolism. Journal of consumer research, 9(1), 4-17.

Berger, J. (2014). Word of mouth and interpersonal communication: A review and directions for future research. Journal of Consumer Psychology, 24(4), 586607.

Bless, H., \& Schwarz, N. (2010). Mental construal and the emergence of assimilation and contrast effects: The inclusion/exclusion model. Advances in Experimental Social Psychology, 42, 319-373.

Blunter, H. (1994). Society as symbolic interaction. In N. j. Herman \& L. T. Reynolds(eds), Symbolic interaction: An introduction to social psychology(pp. 263-265). New York, NY: Altamira Press.

Bock, G.-W., Zmud, R. W., Kim, Y.-G., \& Lee, J.-N. (2005). Behavioral intention formation in knowledge sharing: Examining the roles of extrinsic motivators, social-psychological forces, and organizational climate. MIS Quarterly. 29(1) 87-111.

Buckley, P. J., Clegg, J., \& Tan, H. (2006). Cultural awareness in knowledge transfer to China-The role of guanxi and mianzi. Journal of World Business, 41(3), 275-288.

Burke, P. J. (1991). Identity processes and social stress. American Sociological Review, 56(6), 836-849.

Burke, P. J. (2004). Identities and social structure: The 2003 Cooley-Mead award address. Social psychology quarterly, 67(1), 5-15.

Burke, P. J., \& Harrod, M. M. (2005). Too much of a good thing? Social Psychology Quarterly, 68(4), 359-374.

Carter, M. J. (2013). Advancing identity theory: Examining the relationship between activated identities and behavior in different social contexts. Social Psychology Quarterly, 76(3), 203-223.

Cavender, B., \& Rein, S. (2009). Luxury goods: Still strong sellers. China Business Review, 36(2), 36-39.

Choi, N.-H.. Park. S.-M., \& Lim, A.-Y. (2018). Roles of consumer's social relationship and perceived justice type on service recovery satisfaction. International Journal of Industrial Distribution \& Business, 9(1), 77-88.

Choi, N.-H., \& Dhakal, A. (2017). Roles of power state and message types on restaurant store brand attitude. Journal of Distribution Science, 15(10), 5-14. 
Currás-Pérez, R., Bigné-Alcañiz, E., \& Alvarado-Herrera, A. (2009). The role of self-definitional principles in consumer identification with a socially responsible company. Journal of business ethics, 89(4), 547.

Escalas, J. E., \& Bettman, J. R. (2003). You are what they eat: The influence of reference groups on consumers' connections to brands. Journal of consumer psychology, 13(3), 339-348.

Escalas, J. E., \& Bettman, J. R. (2005). Self-construal, reference groups, and brand meaning. Journal of consumer research, 32(3), 378-389.

Hogg, M. A. (2003). Social identity. In M. R. Leary \& J. P. Tangney(Eds.), Handbook of Self and Identity (pp. 462-479). New York, NY: Guilford Press.

Holbrook, M. B., \& Batra, R. (1987). Assessing the role of emotions as mediators of consumer responses to advertising. Journal of consumer research, 14(3), 404-420.

Jensen, C., Davis, J., \& Farnham, S. (2002). Finding others online: Reputation systems for social online spaces. CHI 2002 Conference on Human Factors in Computing Systems (pp. 447-454). New York, NY: ACM Press.

Kallgren, C. A., Reno, R. R., \& Cialdini, R. B. (2000). A focus theory of normative conduct: When norms do and do not affect behavior. Personality and Social Psychology Bulletin, 26(8), 1002-1012.

Kim, H., \& Markus, H. R. (1999). Deviance or uniqueness, harmony or conformity? A cultural analysis. Journal of personality and social psychology, 77(4), 785.

Lee, J. W., \& Wang, Z. (2018). Spillover effects of foreign direct investment inflows and exchange rates on the banking industry in China. Journal of Asian Finance, Economics and Business, 5(2), 15-24.

Levy, S. J. (1959). Symbols for Sale. Harvard Business Review, 37(4), 203-212.

Ledgerwood, A., \& Chaiken, S. (2007), Priming us and them: Automatic assimilation and contrast in group attitudes. Journal of Personality and Social Psychology, 93(6), 940-956.

McFerran, B., Dahl, D. W., Fitzsimons, G. J., \& Morales, A. C. (2009). I'll have what she's having: Effects of social influence and body type on the food choices of others. Journal of Consumer Research, 36(6), 915-929.

Mussweiler, T., \& Bodenhausen, G. V. (2002). I know you are, but what am I? Self-evaluative consequences of judging in-group and out-group members. Journal of Personality and Social Psychology, 82(1), 19-32.

Oyserman, D., \& Destin, M. (2010). Identity-based motivation: Implications for intervention. The Counseling Psychologist, 38(7), 1001-1043.

Park, C., W., Maclnnis, D. J., Priester, J., Eisingerich, A. B., \& lacobucci, D. (2010). Brand attachment and brand attitude strength: Conceptual and empirical differentiation of two critical brand equity drivers. Journal of Marketing, 74(6), 1-17.

Park, J. K., \& John, D. R. (2010). Got to get you into my life: Do brand personalities rub off on consumers? Journal of Consumer Research, 374), 655-669.

Reed II, A., Forehand, M. R., Puntoni, S., \& Warlop, L. (2012). Identity-based consumer behavior. International Journal of Research in Marketing, 29(4), 310-321.

Schwartz, S. H. (2006). A theory of cultural value orientations: Explication and applications. Comparative sociology, 5(2), 137-182.

Serpe, R. T. (1987). Stability and change in self: A structural symbolic interactionist explanation. Social Psychology Quarterly, 50(1), 44-55.

Shavitt, S., \& Nelson, M. R. (2000). The social identity function in person perception: Communicated meanings of product preferences. Why we evaluate: Functions of attitudes, 37-57.

Sirgy, J. M., Grewal, D., \& Mangleburg, T. (2000). Retail environment, self-congruity, and retail patronage: An integrative model and a research agenda. Journal of Business Research, 49(2), 127-138.

Solomon, M. R. (1983). The role of products as social stimuli: A symbolic interactionism perspective. Journal of Consumer research, 10(3), 319-329.

Stets, J. E. (2006). Identity theory. In P. J. Burke(ed.), Contemporary Social Psychological Theories(pp. 88110). Palo Alto, CA: Stanford University Press.

Stryker, S., \& Burke, P. J. (2000). The past, present, and future of an identity theory. Social psychology quarterly, 63(4), 284-297.

Swann Jr, W. B., Chang-Schneider, C., \& McClarty, K. L. (2007). Do people's self-views matter? Self-concept and self-esteem in everyday life. American Psychologist, 62(2), 84.

Swann Jr, W. B. (1983). Self-verification: Bringing social reality into harmony with the self. Social psychological perspectives on the self, 2, 33-66.

Swann Jr, W. B., Milton, L. P., \& Polzer, J. T. (2000). Should we create a niche or fall in line? Identity negotiation and small group effectiveness. Journal of Personality and Social Psychology, 79(2), 238-250.

Tajfel, H., \& Turner, J. C. (2004). The social identity theory of intergroup behavior. In J. T. Jost \& J. Sidanius(eds.), Political psychology: Key Readings(pp. 276-293). New York, NY: Psychology Press.

Triandis, H. C., \& Gelfand, M. J. (1998). Converging measurement of horizontal and vertical individualism and collectivism. Journal of personality and social psychology, 74(1), 118.

Unger, J. (2006). China's conservative middle class. Far Eastern Economic Review, 169(3), 27.

Varman, R., \& Belk, R. W. (2009). Nationalism and ideology in an anticonsumption movement. Journal of Consumer Research, 36(4), 686-700. 
Wang, C. L., \& Lin, X. (2009). Migration of Chinese consumption values: traditions, modernization, and cultural renaissance. Journal of business ethics, 88(3), 399-409.

Weiss, L., \& Johar, G. V. (2016). Products as self-evaluation standards: When owned and unowned products have opposite effects on self-judgment. Journal of Consumer Research. 42(6), 915-930.

Wiedmann, K. P., Hennigs, N., \& Siebels, A. (2009). Value-based segmentation of luxury consumption behavior. Psychology \& Marketing, 26(7), 625-651.

Wong, N. Y., \& Ahuvia, A. C. (1998). Personal taste and family face: Luxury consumption in Confucian and Western societies. Psychology \& Marketing, 15(5), 423-441.

Zhan, L., \& He, Y. (2012). Understanding luxury consumption in China: Consumer perceptions of best-known brands. Journal of Business Research, 65(10), 1452-1460. 